Andrews University

Digital Commons @ Andrews University

1978

\title{
A Study of the Relation of Rhythm Ability to Reading Achievement in a Sample of Fifth-Grade Students
}

Margarete Moon

Andrews University

Follow this and additional works at: https://digitalcommons.andrews.edu/theses

Part of the Education Commons

\section{Recommended Citation}

Moon, Margarete, "A Study of the Relation of Rhythm Ability to Reading Achievement in a Sample of FifthGrade Students" (1978). Master's Theses. 171.

https://dx.doi.org/10.32597/theses/171

https://digitalcommons.andrews.edu/theses/171

This Thesis is brought to you for free and open access by the Graduate Research at Digital Commons @ Andrews University. It has been accepted for inclusion in Master's Theses by an authorized administrator of Digital Commons@ Andrews University. For more information, please contact repository@andrews.edu. 
ABSTRACT

A STUDY OF THE RELATION OF RHYTHM ABILITY TO READING ACHIEVEMENT IN A SAMPLE

OF FIFTH-GRADE STUDENTS

by

Margarete Moon

Chairperson: Mijilie Youngberg 


\title{
ABSTRACT OF GRADUATE STUDENT RESEARCH \\ Thesis
}

\author{
Andrews University
}

Department of Education

\begin{abstract}
Title: A STUDY OF THE RELATION OF RHYTHM ABILITY TO READING ACHIEVEMENT IN A SAMPLE OF FIFTH-GRADE STUDENTS

Name of researcher: Margarete Moon

Name and title of faculty adviser: Millie Youngberg, Ed.D.

Date completed: August 1978
\end{abstract}

\section{Problem}

Recent research in the area of development of language skills indicates a trend toward exploration of the role of the auditory modality in learning to read. Rhythm is frequently thought to be an important contributing element. A correlational study was undertaken to discover the extent to which a relationship exists between rhythm ability and reading achievement in a sample of middle class fifth-grade children of both sexes.

\section{Method}

One hundred and thirty-seven fifth-grade students participated in the study. Of these, 63 were males and 74 were females. Pearson product-moment correlation coefficients were found between 
scores of rhythm ability and scores of reading achievement, on three levels of overall ability for the boys and the girls, and for the entire sample. Rhythm scores were obtained by administering the rhythm test of the Drake Musical Aptitude Tests. Reading achievement scores and scores of overall achievement were derived from the Iowa Tests of Basic Skills, Form Five, which had been administered the previous semester.

Results

A significant positive correlation between rhythm ability and reading achievement was found to exist for the sample as a whole, and for the high achieving subgroup $(\mathrm{p}<.10)$, with no difference in the magnitude of the correlation for either sex. No significant correlation appeared to exist for the average and low achieving subgroups of either sex. However, a comparison of the mean scores of rhythm ability and reading achievement indicate that while overall ability decreases, mean scores for rhythm and reading a1so decrease.

\section{Conclusions}

A relationship between rhythm ability and reading achievement does seem to exist for the children of this sample. However, the predictive value of rhythm ability is limited to the high overall achievement 1evel. As a diagnostic tool for individual children rhythm ability is only one of many interrelated factors to be considered in the assessment of learning difficulties, and its value is questionable. Rhythm being a fundamental element, it merits consideration as an enriching component of the elementary 
curriculum, which might have beneficial effects on other areas. The concept that rhythm training promotes the development of reading skills is inadequately defined and not well researched, and requires further investigation. 
Andrews University

School of Graduate Studies

A STUDY OF THE RELATION OF RHYTHM ABILITY TO

READING ACHIEVEMENT IN A SAMPLE

OF FIFTH-GRADE STUDENTS

A Thesis

Presented in Partial Fulfillment

of the Requirements for the Degree

Master of Arts

by

Margarete Moon

August 1978 


\section{A STUDY OF THE RELATION OF RHYTHM ABILITY TO READING ACHIEVEMENT IN A SAMPLE \\ OF FIFTH-GRADE STUDENTS}

\section{A thesis presented}

in partial fulfillment of the requirements

for the degree

Master of Arts

\section{by}

Margarete Moon

APPROVAL BY THE COMMITTEE:
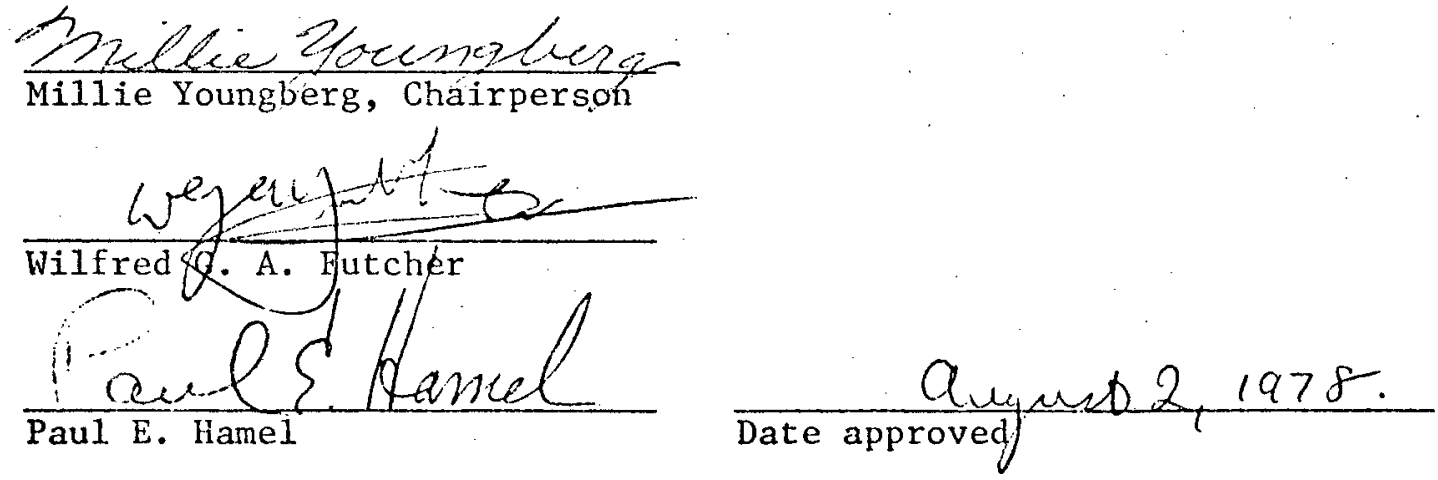
TABLE OF CONTENTS

LIST OE TABLES . . . . . . . . . . . . . . . . iv

ACKNOWLEDGMENTS . . . . . . . . . . . . . . . . v v

Chapter

I. INTRODUCTION . . . . . . . . . . . . . . 1

The Problem .................. 1

Purpose of the Study ............... 1

Justification of the Study . . . . . . . . . . 1

Hypotheses................. 2

II. REVIEW OF LITERATURE . . . . . . . . . . . . . . 4

Introduction............... . . 4

Audition and Language Skills . . . . . . . . 5

Sensory Integration .. ............ 12

Music, Rhythm, and Language Skills . . . . . . 15

Conclusions.............. . . 26

III. RESEARCH DESIGN . . . . . . . . . . . . 30

Introduction ................. 30

The Population and Sample........... 30

Data Required . . . . . . . . . . . . . 31

Instruments used for Collecting Data. . . . . . 31

Procedures for Collecting Data.......... . 35

Analysis Methods . . . . . . . . . . 38

IV. PRESENTATION AND ANALYSIS OF DATA . . . . . . . . . . 39

Basic Data ................ 40

Test of Hypotheses............... 41

V. SUMAARY, CONCLUSION, AND RECOMMENDATIONS . . . . . . 44

Findings ................. . 47

Discussion ................. 47

Recomnendations .............. 48

APPENDIX . . . . . . . . . . . . . . . . 51

SELECTED BIBLIOGRAPHY • . . . . . . . . . . . . . 58 


\section{LIST OF TABLES}

1. Means on the Three Variables . . . . . . . . . .

2. Correlation Coefficients between Reading Achievement and Rhythm Ability for all Groups . . . . . . . . 42

3. Comparisons of Correlation Coefficients....... . 43

4. Raw Data for High Achieving Girls . . . . . . . . 52

5. Raw Data for Average Achieving Girls . . . . . . 53

6. Raw Data for Low Achieving Girls . . . . . . . . 54

7. Raw Data for High Achieving Boys . . . . . . . 55

8. Raw Datá for Average Achieving Boys . . . . . . . 56

9. Raw Data for Low Achieving Boys . . . . . . . . 57 


\section{ACKNOWLEDGMENTS}

Though limited in size, this study represents the cooperation of numerous individuals who have given freely of their time, expertise, and encouragement. Sincere thanks is expressed to members of my thesis committee. Their encouragement meant much to me. Dr. Millie Youngberg, chairman of the committee, asked intriguing questions and inspired me to search for answers. Dr. W. G. A. Futcher generously gave his help on the design of the study and spent much time on the analysis and interpretation of the results, initiating me into some of the mysteries of educarional research. Dr. Paul Hamel gave valuable advice on the portions of the study concerning music and rhythm, and offered pertinent criticism during the final writing stages.

Gratitude is expressed to Alfred Berg, principal of Sylvester Elementary School for permitting access to the required data, and to Laura Jean Sill, music instructor, for offering instruction time for testing the students. For her humor, her generous encouragement, for material and emotional support, I thank my mother-in-1aw, Leona Moon. By caring for my young daughter at crucial times, she freed my hands to write. Though neglected at times, my husband, Donovan, undergirded me with patience, loving concern, and constant encouragement. Most of a11, I thank my heavenly Father for the privilege of studying, the joy of learning, and the challenge of sharing. 
CHAPTER I

\section{INTRODUCTION}

\section{The Problem}

The available research evidence and observations of the effect of music, and of the rhythm component in particular, on the development of language and reading skills, and the apparent lack of rhythm ability in many children with learning disabilities seem to suggest that a relation exists between reading and rhythm ability. The relationship of rhythm to reading has not been widely studied and seems to merit investigation on the basis of the attention it receives.

\section{Purpose of the Study}

This study is designed to discover, by means of a correlation analysis, the extent to which a relationship exists between rhythmic perception and reading ability in a sample of middle class fifth-grade children of both sexes. Also, a comparison was made of the magnitude of the relationship for three levels of overall ability and for the two sexes.

\section{Justification of the Study}

In recent research concerning the development of language skills, especially in relation to reading, there has been a trend to explore the role of the auditory modality (Johnson and Myklebust, 
1967; Flynn and Byrne, 1970; Finkenbinder, 1973; Richie and Aten, 1976; U.S. Department of Health, Education and Welfare, 1969). Numerous reports indicate apparently effective results of integrating elements of music with the elementary school curriculum, particularly in the language arts (Block and Leiberman, 1968; Cohen, 1974; Gibbs, 1970; Hamm, 1971; Harper, Flick, Taylor and Waldo, 1973; Hurwitz, Wolff, Bortnick and Kokas, 1975; Uh1, 1969; Yaakob, 1973).

The component of rhythm is singled out frequent1y and is acclaimed to be a salient element in language acquisjtion, conceptualization of temporal and spatial elements, and the classification and organization of auditory stimuli (DeHirsch, Jansky and Langford, 1966; Kaliski, 1977; Kephart, 1960; Rampp, 1971). More genera11y, rhythm is said to aid auditory memory and the ability to understand language (Kallan, 1972; Rejto, 1962), influence body concept development through kinesthetic awareness and control (Cohen, 1974; Rosenkrantz, 1974), and affect the ability of a child to learn to read (Block and Lieberman, 1968; Cohen, 1974; Drake, 1964; Kaliski, 1977; Yaakob, 1973). Some have observed that a lack of rhythm awareness or a deficiency in rhythm ability is a prominent characteristic of many children experiencing learning disabilities (Drake, 1964; Kaliski, 1977; Kephart, 1960; Myklebust, 1967; Rampp, 1972).

\section{Hypotheses}

The objective of this study was to discover the extent to which a relationship exists between reading ability and the ability 
3

to perceive and maintain auditory rhythm. The hypotheses set forth were:

1. A significant positive correlation will exist between reading achievement and auditory rhythm ability.

Assuming the validity of hypothesis 1 , the following hypotheses were further proposed:

2. There will be no difference between the magnitude of the correlation for children of different sexes.

3. There will be no difference between the magnitude of the correlation for children of different general ability. 
CHAPTER II

REVIEW OF LITERATURE

\section{Introduction}

The review of literature which follows encompasses three areas which are inseparable and also which, when viewed as parts of a whole, aid in an understanding of current issues in elementary language arts education. Prerequisite to a discussion of rhythm as a factor in reading is an overview of audition in relation to learning. Rhythm is most easily understood against the dimension of time; thus of necessity an understanding of the auditory field, which functions in the temporal dimension, must form the foundation on which to build a discussion of this nature.

The first section reviews selected literature in the area of audition in relation to reading and, more generally, to the development of language skills. The primary factors discussed are perception, discrimination, memory and auditory processing. The second section is a brief review of current literature on the topic of sensory integration, specifically auditory-visual integration, and its relation to reading. A discussion of the element of rhythm concludes the review of literature. The focus is on observations reported in popular education journals as well as on more technical, well-researched findings on the effect of rhythm on language skills. The review of literature ends with a brief 
discussion of controversial issues in the areas of audition and learning and the effects of music and rhythm on language ski11s development.

\section{Audition and Language Skills}

Someone has said, "If children do not learn the way we teach them, we must teach them the way they learn" (Dunn and Dunn, 1977, p. 48). In the field of reading this acquires special significance as educators attempt to help children comprehend the written language code and utilize it to full advantage.

Reading is the most basic requirement of the language arts curriculum in the primary grades, and reading English is not a simple task. Attainment of skill in reading is directly related to mastery of many component skills, such as dissecting spoken words into constituent sounds in their temporal order, recognizing and disciminating letters of the alphabet, responding to the direction in which words are spelled and their continuous order, recognizing printed words, learning that their meaning is analogous to spoken words and learning to reason and to think about what one reads. Traditional English orthography presents a major challenge as the child becomes familiar with the 2000 variants in the way the 26 symbols of the alphabet are used to make the approximately 40 sounds of English speech (Rampp, 1971, p. 309).

Children learn in many ways. Since input precedes output, it is important for an educator to be aware of the sensory channels used in learning and to recognize to some extent the efficiency with which a child is able to use his sensory modalities. 
Learning by the visual sense has been explored extensively in the past, but only in the last decade has there been a growing interest in the assessment of auditory learning (Finkenbinder, 1973; Flynn and Byrne, 1970; Johnson and Myklebust, 1967; Richie and Aten, 1976; Vogel and McGrady, 1975). The increased concern for children with learning difficulties has helped to foster an interest ir identifying deficit areas (Gallagher, 1960). Auditory learning, and more recently tactual and kinesthetic learning, are receiving close attention.

Some educators feel that there is a physio-sensory predisposition which makes one an "auditory person" or a "visual person," and that it creates a basic difference in learning and behavioral styles according to the way one senses the environment (Lee and Young, 1974). Whether or not this is true, audition is the primary channel for language acquisition (Johnson and Myklebust, 1967, p. 66).. Myklebust (1954) and Wepman (1960) stress the importance of auditory function in spoken language and reading. Strag and Richmond (1973) and Rosner (1973) concur that learning to read depends heavily on auditory skills. Stüdies by Berg (1958) quoted in Johnson and Myklebust (1967) indicate a relation between low listening ability and low reading ability, and between high reading ability and high listening ability.

The primary areas of concern in the auditory component of reading are perception, discrimination and memory. Numerous scholarly reports discuss these factors, of which a few have been selected for review in this study. The importance of auditory perception in beginning reading, in particular the ability to segment 
sounds that correspond in sequence to letters or letter groups, is emphasized by Durrel1, quoted in MacGinitie (1967). Auditory perception problems, though not as obvious, may be as formidable as visual perception problems to a child beginning reading. The perception of speech is a very complex matter, and MacGinitie urges that auditory perception receive close examination by educators and researchers (MacGinitie, 1967, p. 538). Rampp (1971) discusses extensively the auditory role in learning and its application to the development of language skills, and in particular to reading. His insights on auditory perception are based on broad clinical experience and research. Rampp characterizes perception as constituting a whole. It forms a "gestalt." Secondly, Rampp states that perception is always figure against background. There is no perception without selection. In visual perception, "figure-ground" refers to perception of a configuration superimposed on spatial background. Similarly, in auditory perception, acoustic stimuli are perceived against an array of other sounds that are temporarily screened out. Thirdly, perception is developmental, going from the simple to the complex (Rampp, 1971, p. 299). Rampp defines perception as the association of meaning with sensation. It is a matter of ordering or orienting rather than knowing. Because auditory perception is fundamental in human behavior and language development, Rampp deplores the paucity of research regarding auditory perception. The most crippling effect, says Rampp, of an auditory perceptual disturbance, is a reading problem in the initial school experience. Rampp (1971) states that "reading is primarily a 
visual symbol system requiring many auditory integrities including the ability to discriminate differences and similarities in sounds, to perceive a sound within a word, to synthesize sounds into words, and to separate them into syllables" (p. 310).

Current literature on learning disabilities and reading disorders frequently refers to the phenomenon of disturbed auditory perception. Myklebust (1954), among others, categorizes and discusses the etiology of various auditory perceptual disorders. This is peripheral to the present study, except to acknowledge that this type of disorder can be devastating to the person encountering it. Linguistically disturbed children seem to be overwhelmed with unprocessed sensations which they are unable to organize and order into meaningful messages (Berry, 1969). To the child experiencing an auditory perceptual disorder all sounds have equal importance and he is incapable of selectivity. The major sensory pathways are inundated with disorganized impulses (Berry, 1969; Rampp, 1971, p. 305). Many areas of audition are affected, including auditory discrimination, sound blending, synthesizing, auditory memory, serial order memory, and reauditorizing sounds and words (Johnson and Myklebust, 1967, p. 174; Rampp, 1971, p. 305).

MacGinitie believes that an auditory perceptual disorder may initially contribute to a language or reading disability. However, by the time the reading disability is recognized and studied, the child may have matured in auditory perception or compensated for the disorder in some way, yet retain the reading problem (MacGinitie, 1967, p. 538). 
Auditory discrimination is a second factor in audition which research evidence agrees has a strong relation to reading (Durrell and Murphy, 1963; Dykstra, 1966; Flynn and Byrne, 1970; MacGinitie, 1967; Oakland, Williams and Harmer, 1973). Robinson (1952), quoted in Johnson and Myklebust (1967), found that a functional auditory disturbance such as inadequate auditory discrimination or insufficient auditory memory span for sounds was present in about 46 percent of her sample with reading disabilities. These findings are supported by Wepman (1960) who found a positive relationship between poor discrimination and poor reading. Wepman defines auditory discrimination as the "capacity to distinguish between phonemes or individual sounds in speech" (Wepman, 1960, p. 325). The ability develops at different rates, maturing at about eight years, according to Wepran, and a few individuals never develop the capacity to any great degree.

Deficiencies in auditory discrimination seem to be the most serious in the primary grades; in the intermediate levels the "auditory discrimination ability seems to fade rapidly as a contributing variable to underachievement in reading (Strag and Richmond, 1973, p. 448). In a study of 632 pupils, Dykstra (1966) reports a significant relationship between pre-reading auditory discrimination and reading achievement at the end of first grade. Results of the study also indicated that girls were superior to boys in auditory discrimination skills. These findings seem to be supported by findings of Wepman (1960), who believes that a strong positive relation exists between poor discrimination and poor reading, with 1ittle relation to intelligence. Silent reading comprehension and 
phonic analysis especially depend on the ability to comprehend spoken words and discriminate similarities and differences between speech sounds (Oakland, Williams and Harmer, 1973).

A third factor in audition which recent research agrees to be vital to the development of reading skills is the ability to retain auditory stimuli, and in particular stimuli which are presented serially (Badian, 1977; Corkin, 1975; Falk, 1973; Johnson and Myklebust, 1967; Richie and Aten, 1976). Verbal communication requires that the order of the information must be recalled as well as the information itself. Studies of memory and attention factors in children with specific learning disabilities demonstrate specific deficits in memory or organization capacity. There is also some indication that the stimulus rate is a major determinant in the memory storage process (Senf and Freund1, 1971). Corkin (1975) comments that in the early research on dyslexia the trend was to relate the difficulties to perceptual disorders. She states, however, that recent research suggests that "marked reading disorders in children may be due to a general deficit in ordering items sequentially, independent of the symbolic nature of the reading process" (p. 87). Corkin (1975) and Richie and Aten (1976) concur that retarded readers are inferior to adequate readers on tasks requiring auditory retention of verbal and nonverbal auditory stimuli. Corkin studied average and inferior readers and their performance on visual and auditory serial ordering tasks. She found that average readers surpassed inferior readers at all ages studied: preschool, elementary, and junior high school. One interesting result of the study is that, in inferior readers, 
performance broke down in face of delay conditions or competition among items in an overloaded immediate memory store (Corkin, 1974). Corkin's fjndings are supported by results of research by Badian (1977), who investigated the nature of inferior performance of retarded readers on auditory-visual integration tests, and found that auditory memory was a significant factor in the divergent results of performance of retarded readers and adequate readers. In contrast to adequate readers, the retarded readers' performance deteriorated sharply as the memory demands increased.

As defined in a study by Richie and Aten (1976), "auditory retention of sequential stimuli is the ability of an individual to store briefly and recall accurately a selected number of serially presented auditory stimuli" (p. 312). Richie and Aten found that performance of children with reading disabilities was significantly inferior to performance of a matched group of children without reading disabilities. Experimental measures requiring auditory retention were rhythmic and durational patterns, and verbal stimuli consisting of phonemes, words, sentences, and rearranged syntactic structures (Richie and Aten, 1976). Richie and Aten conclude that "the reading process, an integral part of language acquisition, requires one of the most complex forms of sequence processing" (p. 312)

That a significant short term sequential memory factor may be involved in auditory-visual integration, and that it has an effect on reading ability, has been suggested or implied by a number of researchers, including Birch and Belmont (1964), Sterrit and Rudnick (1966), and Vande Voort, Senf and Benton (1972). 
Further investigation and study of the relation of auditory skills to reading ability is urged by many investigators. Richie and Aten (1976) suggest that reading evaluations

- . include assessment of the individual's ability to master the acoustic parameters of oral language, i.e., rhythm, duration, phonemic similarities, order of stimuli, and number of stimuli. . . Children in need of reading remediation should receive more adequate training in auditory skills, and definitive research is needed to determine more precisely the specific relations of auditory skills to reading proficiency. (p. 318)

\section{Sensory Integration}

A large volume of research has been presented since the mid 1960 's regarding sensory integration, particularly audio-visual integration ability and its relation to reading skills. Prominent research on this topic is presented by Berry (1967), Birch and Belmont (1964, 1965), Ford (1967), Jorgensen and Hyde (1974), Kahn and Birch (1968), Reilly (1971), and Sterrit and Rudnick (1966).

Rampp and Covington (1972) refer to the act of reading as

"a visual symbol system requiring many auditory integrities" (p. 310). Birch and Belmont (1964) state more specifically that "learning to read as an educational task requires the ability to transform temporally distributed auditory patterns into spatially distributed visual ones" (p. 852). Although the specific nature of auditory-visual integration ability is not well understood, and its relation to reading skills is controversial, several facts of interest to educators have emerged.

1. Some researchers believe that judgments of auditoryvisual equivalence are positively related to reading proficiency (Birch and Belmont, 1964, 1965; Kahn and Birch, 1968; Robinson, 
1973; Ward, 1977). Birch and Belmont (1964), in their original study, found that young children have difficulty in matching temporal rhythms of taps against visual sequences of dots. A similar type of difficulty was found to exist in backward readers. Most of the subsequent studies have been based on a similar conceptual framework or on an adaptation of the Birch and Belmont matching tasks.

2. Auditory-visual integration seems to be developmental. Evidence resulting from an ingenious study with infants seems to indicate that the sensory systems are integrated to some extent during early infancy, if not from birth. Allen, Walker, Symonds and Marcel1 (1977) found that infants as young as seven months are capable of recognizing equivalent amodal information, whether it is presented within or across modalities. Auditory-visual integration increases with age (A1exander, 1977, Jorgensen and Hyde, 1974), and increases the most rapidly between Kindergarten and second grade (Birch and Belmont, 1964). According to Kahn and Birch (1968), auditory-visual integration skill develops throughout the elementary years, and continues to be significantly related to reading performance at least to the sixth grade. Reilly (1971) found that the relationship appeared to be the most significant in grades two to four for males, grades one to three for females, and present but not significant by grades four and five for females and males, respectively.

3. Auditory-visual integration is a significant correlate of reading, independent of IQ (Birch and Belmont, 1964, 1965; Berry, 1967; Jorgensen and Hyde, 1974; Kahn and Birch, 1968; 
Sterrit and Rudnick, 1966). This conflicts with findings of Ford (1967) and Ward (1977) who found that intelligence makes a significant contribution to auditory-visual integration.

4. Sex is not a significant variable according to Ward (1977) and Muehl and Kremenak (1968). However, Rei11y (1971) and Jorgensen and Hyde (1974) maintain that auditory-visual integration and reading proficiency seem to be related and that sex makes a significant difference at some grade levels.

Controversial evidence is presented by some researchers, suggesting that, in studies of the nature previously described, factors other than audio-visual integration are responsible for distinguishing retarded readers from adequate readers. Results of studies by Vande Voort, Senf and Benton (1972) and Vande Voort and Senf (1973) contradict the Birch and Belmont hypothesis and subsequent findings that auditory-visual integration is a critical. skill in reading. They believe rather that sensory and/or perceptual factors account for deficits in auditory-visual integration, and that it is not a salient characteristic in deficient readers.

Bryden (1972) administered tasks requiring same-different judgments for various combinations of auditory-sequential, visualsequential and visual-spatial patterns to matched groups of good and poor readers. The results demonstrated that poor readers were deficient in all matching tasks, "indicating that their deficiency is not specific to auditory-visual integration or rhythm perception, but is a more general one, possibly involving verbal coding" (p. 824). 
Rhythm appears to be common to the tasks of all the studies mentioned in the capacity of auditory-visual integration. In these studies, sequences of temporal stimuli such as taps or pure tones, produced either mechanically or manually, were to be matched to equivalent visual patterns, consisting of dots and dashes or similar spatially distributed configurations. One might speculate whether rhythm could also be a contributing factor in the relation of sensory integration and reading.

\section{Music, Rhythm, and Language Skills}

Rhythm, whether visual, auditory or kinesthetic is an element little understood but greatly exploited. Rhythm is at times referred to in the literature of language skills development, which includes reading. Support for its inclusion, however, is limited. While discussions of assessment and remediation of learning difficulties refer frequently to rhythm disturbances and to the perception of rhythm, little research is available on the nature of the relationship.

It appears, however, that rhythm and music, the larger medium to which it is related, are being much experimented with in educational practice. There is in current educational literature an increasing enthusiasm for utilizing music as a methodological tool in the elementary education curriculum. It is believed that music has a positive effect on motivation, various 1istening skills, auditory perception and discrimination, development of rhythm sense, diction, visual perceptual skills, and motor development (Block and Lieberman, 1968; Cohen, 1974; Johnson, 1976; Lehman, 1969). 
Music and rhythm activities add sensory experience in the beginning reading program and they help the child interpret abstract symbols. Activities such as listening to songs, dancing, and reading the words of songs are suggested (Block and Lieberman, 1968). Children react quite readily to music mood, whereas words may be a barrier to interpretation (Block and Lieberman, 1968; Fitouri, 1972). Uhl (1969) believes that syllabication and diction and discrimination between consonant and vowel sounds are aided by singing, and that rhythm ability and auditory acuity are directly aided by music. Music is a communicative language that moves the child through song and dance, and which can stimulate, support and inspire a beginning reading program, according to Cohen (1974). He suggests that pattern awareness with music activities aids visual perceptual awareness, that listening to music aids auditory awareness and that kinesthetic control, such as in dance activities, aids body concept development. Some writers feel that music is useful and effective in implementation with all subjects (Johnson, 1976; Lehman, 1969). In the application of music instruction to reading, Yaakob (1973) states that

Many of the reading readiness skills such as auditory discrimination, visual discrimination, direction, imitation, interpretation, voice expressions, listening, word meanings out of context and in context are emphasized in the teaching of musical skills for simple melodies and nonsense melodies. (p. 577)

High priority is given by Yaakob to "rhythm and the range of thousands of rhythm sounds" in teaching auditory discrimination as a readiness skill (p. 577). 
Rosenkrantz (1974) suggests that rhythm and movement activities, integrated with music, reinforce and assist motor development. The perceptual motor areas which she believes to be related to music activities are locomotion, balance, laterality and body image. She also believes that the use of rhythm "will help to develop awareness of timing that can be carried over into such other areas as counting, writing, and reading" (p. 59).

Teaching methods broadly based on the educational philosophy of Zoltan Kodaly are impressively successful judging by reports which have emerged from some experimental studies. The Kodaly system is a program of music education for young children, beginning at Kindergarten level. Training is based on a sequential curriculum teaching the basics of music in the framework of simple folksongs, and is aimed at all children. It is a many-faceted perceptual and cognitive program, thus having implications for development of skills.in non-musical areas. Some of the techniques used are signs, games, clapping, reading musical notes, rhythmic notation and singing. Rhythmical skills are stressed and children become involved in the musical activities on a strong sensory and motor basis. In actual experience, the instructor may place visual symbols of a rhythmic structure on the blackboard, then transform the symbols to body experience by tapping out the rhythm on a child's shoulder. Or the rhythmic structure of a folk song may be sung, then experienced by body movement. Or the structure may be built spatially by positioning the children at various distances from each other, representing the relationship of notes in time, demonstrating temporal and spatial processes and relationships. 
The exercises and games of the music program provide a basis for development of visual and auditory perceptual skills, reinforced with motor, tactual and kinesthetic functioning (Hurwitz, Wolff, Bortnick and Kokas, 1975). Harper, Flick, Taylor and Waldo (1973) report on a study of the effects of "Education through Music" which is rooted in the Kodaly educational philosophy and which aims to help the child coordinate the sense of hearing with imagining, feeling and moving. Test results of the preparation for first grade of six kjndergarten classes favored the group which had been exposed to Education through Music (Harper et a1., 1973). Non-musical effects of exposure to the Kodaly Music Training Program are reported in depth in results of a study by Hurwitz et a1. (1975). The study compared the performances of two matched groups of primary grade children on tasks of temporal and spatial abilities. One group received intensive exposure to the Kodaly Music training program, while the control group did not. Results showed that the music group performed better than the control group on temporal and spatial tasks. Furthermore, children who had received the music instruction performed better on reading tests. According to Kokas, who has studied the effects of the Kodaly method on Hungarian children who receive intensive music education on a daily basis, superior performance is evidenced in study habits, reading and arithmetic. Exploratory research in Hungary indicates that the Kodaly method may have an impact on visual observation, spelling, language learning and movement (Hurwitz et a1., 1975).

These results concur with findings of a pilot research project conducted in Australia which employed a teaching method 
based on Kodaly principles and which was integrated with the usual activities of Kindergarten and first grade. Apart from the expected development of musical skills, evidence is emerging which indicates significant effects on other learning performance and on personality adjustment. Trends of a pilot survey of 150 first grade students indicate that the Kodaly group showed increased capacity to attend and listen, and demonstrated a significantly higher level of performance on such tasks as draw-a-man, copying and recalling perceptual forms, simple tests of rhythmic auditory recall, and vocabulary. No difference was noted on performance of digit span tests. Herbert (1974) summarizes the benefits of a musically based program of education:

It is encouraging and stimulating to find a comprehensive programme of education which has its origins in sound, and which provides a secure initial basis for training in auditory areas. The capacity for communication, which is one of the primary and ultimate aims of education, develops early with a marked degree of competence and security. Kodaly Education through Music may well provide a unique foundation for the formal reading programme and a background of confidence for later learning situations, quite apart from the obvious cultural advantages inherent in a musically based programme of education. ( $p .22)$

Hurwitz et al. (1975) believe that the musical training with emphasis on motor rhythm in the early elementary curriculum may influence "sequencing behavior and tasks of spatia1 functioning," which will. have an effect on academic performance in such areas as reading ( $p \cdot 174)$. Furthermore, research results indicate that musical training based on Kodaly principles was "found to improve the performance of normal children on a wide range of psychological test measures, including stability and accuracy of sensorimotor rhythmic behavior, sequencing of verbal 
symbols, solution of problens of perceptual restructuring and spatial abilities" (Hurwitz et a1., 1975, p. 50). Reading achievement test scores were higher for children who had received Kodaly music training than for children of the control group. Hurwitz et al. admit that it is a complicated psychological mechanism by which the Kodaly method influences the cognitive functions, and urge further study of this seemingly effective method which may provide one avenue to facilitate learning in the primary grades. Music, and in particular the element of rhythm, has been suggested by a number of educators to be of value in the remediation of learning difficulties in the language arts, especially in reading. Thompson (1966) observes that "music is still another 'communication function' that is related to language abilities. In many ways, reading a music score, sense of rhythm, tone sensitivity (perfect pitch versus tone deafness), motor disability, etc., cannot be divorced from language abilities and disabilities" (p. 59). Rejto (1973) reported a case study of a child with perceptual difficulties, who was aided by visual, aural and tactual training using the piano as a medium. She claims that significant gains were made in language skills, auditory and visual perception, sensory-motor integration, symbolic representation and memory during the six months of multisensory training. Rejto believes that rhythm is a salient element which affects auditory memory and the ability to understand language, and that the language problems of children can be helped by the rhythmic training offered through music lessons. Ashlock (1969) suggests skipping, rhythm band, dancing, marching and movement or motion exploration as therapeutic 
activities for children with learning disabilities.

Robison (1971) suggests that emotionally disturbed and disadvantaged persons may be aided by rhythm therapy. She states that "listening stimulates or calms, according to tempo and dynamics, and our own production of rhythm, the 'power of rhythm to energize and order' becomes a part of our being and aids our physical, mental and emotional development" (p. 42). She suggests the use of drums, cymbals, and other percussion instruments to release emotion.

A remedial approach using kinesthetic rhythmic activities was used to good advantage with an eight year old hyperactive child who had not yet learned 1etters and sounds. Segel (1976) found that "concentration had to involve movement of some kind. Learning the alphabet, the days of the week, the months, even the sounds of letters, all took place with activity" (p. 221). Activities employed were rocking in the rocking chair while listening to the therapist, bouncing a ball while learning the alphabet, walking down steps while learning the days of the week, and doing push-ups while learning the months of the year.

An interesting approach, based primarily on experience, has been amalgamated by Kaliski (1977), founder of several schools for children with learning disabilities. Kaliski's primary concern is with perceptual strengths and deficits of the students. Kaliski feels that rhythm, rhythmic speech and special visual and/or auditory stimuli are educationally therapeutic. Beside auditory verbal training, she also stresses non-verbal auditory training on a very elementary level. Differentiating common sounds and locating them, 
auditory figure-ground activities, sequences of sounds, and matching sounds are some of the techniques used in auditory perceptual

training. Kaliski stresses rhythm and rhythmic speech, and suggests that "singing to the child brings good results" (p. 215).

A remedial teaching program integrating music with learning tasks for a child with severe learning difficulties is reported by Kaliski (1977). Remediation capitalized on the child's strengths in the auditory modality coupled with her interest in music and rhythm. Painting to music resulted in improved coordination during the activity, rhythmic clapping helped her recall rhymes, rhyme words and poetry. Difficulties in eye-hand, eye-foot coordination, balance, and body image improved with involvement in music classes where she learned to manipulate drumsticks, castanets and the triangle. Use of the piano resulted in improved fine finger dexterity and coordination and development of the small hand muscles. Regarding music and rhythm in teaching children with learning difficulties, Kaliski states that

Music and rhythm are excellent approaches for auditory-vocal stimulation. Those media, though non-verbal in their origin, can be used effectively by a capable teacher who does not necessarily have to be an expert in music. The non-verbal area of music can be translated into symbolic verbal units which will benefit the Specific Language Disabilities child. (p. 217)

Others concur that music may be a useful vehicle for training "special children," especially in auditory perceptual areas. If music can help in the development of language, its use should be explored and developed (McDonald, 1975). Johnson and Myklebust (1967), in deliniating educational procedures for children with generalized auditory deficits resulting in learning 
disturbances include, among other items, capitalizing on auditory inflection and rhythm patterns, sequentialization, imitating sounds and rhythm patterns, emphasizing rhythmic sequences of words, and matching rhythms. Addressing evaluative procedures of children with auditory perceptual disorders, Rampp (1972) states that

Some estimate should be made of the child's ability to discriminate pitch and rhythm. Many children cannot differentiate pitch differences or changes whether the stimulus is pure tones or sustained phonation. Also, many of these children cannot imitate phonated rhythm sequences presented by the examiner or parent. (p. 315)

Some researchers believe that poor readers may coordinate well but may be arhythnic, and that developing a child's sense of rhythm is important in helping him learn to read (Drake, 1964). Evidence from studies at reading research institutes at Berea College, Kentucky, and Freyburg Academy, Maine indicates "that children who have extreme difficulty in decoding words and who exhibit bizarre spelling and writing patterns usually have very little sense of rhythm" and that "failure to develop rhythm usually predicts a failure in symbolic functions" (Drake, 1964, p. 202). Joseph Firszt of Berea College comments that "the dyslexic child is unable to express himself in rhythmic terms, whether it be in reading, handwriting, dancing, handclapping, playing a musical instrument or spelling" (Drake, 1964, p. 203). These findings seem to concur with Kephart's belief that many of the problems of auditory span, temporal order in series information and similar dysfunctions may be related to an inability to establish and/or maintain rhythm patterns (Kephart, 1960, p. 235), and that children 
with learning disabilities are prominent in the lack of consistent rhythm patterns.

Although rhythm in a qualitative sense, is difficult to define, its function in the temporal dimension can be observed. "Rhythm . . in contrast to time, is the organization of time relationships" (Lundin, 1967, p. 111). DeHirsch, Jansky and Langford (1966) suggest that rhythm helps to orient one in time, as any sequence represents an organization in time, and "learning to perceive, to process, to store and to recall the serial order of information is a requisite for later reading activities" (p. 88). Similarly, Kephart (1960) states that "rhythm is important in kinesthetic and tactual problems since much of the information which we obtain from the senses is probably aided and initiated by ability to establish and maintain rhythm relationships. In the auditory field information is kept classified and organized through the imposition of rhythm upon auditory stimuli" (p. 235). Auditory stimuli exist only within the framework of the temporal dimension and are organized for retrieval from the memory by their serial order or rhythm pattern.

Kephart maintains that the temporal dimension function is characterized by maintaining stable, constant rhythm, as opposed to the temporal memory function which pertains to perceiving and differentiating between rhythm patterns. Kephart further suggests that, for children who exhibit disturbed rhythm in motor activities, such as jumping jacks and drawing double circles, the concept of a temporal unit is ill defined, or the temporal dimension lacks consistency. Critchley (1962) concurs that a disordered temporal 
conception may characterize the dyslexic child.

The foundation for comprehending the temporal dimension is based on motor activity such as infants and young children engage in, perhaps as an exploratory method in conceptualizing simultaneity and sequentialization (Kephart, 1960, p. 177). An example given by Kephart is the infant who contrasts simultaneous movement with alternate movement, as in pounding the table with both hands, and pounding the table with alternate hands. He suggests that, since a coordinated motor performance requires differentiation of simultaneity and sequence, an abstraction of this activity may well form the basis of a concept of the temporal dimension. Motor rhythm is defined as the "ability to perform a movement or series of movements with a consistent time interval" (Kephart, 1960, p. 177). Some writers suggest that rhythm ability is not inherent but can be improved by training (Lundin, 1967, p. 114) and that individual differences exist in the capacity to respond to rhythm. DeHirsch, Jansky and Langford (1966) believe that training of children who are experiencing rhythm difficulty must begin on a nonverbal, preferably kinesthetic level (p. 88). Drake suggests activities such as top spinning, yo-yo tossing, rope jumping and folk dancing for development of rhythm ability (Drake, 1964, p. 204). Auditory and visual rhythm are both receptive. However, unless the child has a motor component for an auditory rhythm, the rhythm may well escape the child, and he may not even be aware of the rhythmic quality of the auditory stimulus (Kephart, 1960, p. 178). Thus the development of kinesthetic rhythm seems to be fundamental both to development of a concept of the temporal 
dimension and to the complex skill of comprehending rhythm patterns.

Another characteristic of poor readers, related to rhythm ability, is the tendency of the eyes to move in a disorganized manner, rather than back or forward to pick up vital clues (Kephart, 1960, p. 179). The effective reader is characterized by systematic exploration of the visual field which is too extensive to gain in one fixation. Rhythm superimposes a pattern to organize the exploration so the fixations can be integrated, and the reader is able to decode the graphic symbols. Kephart believes that, to be effective, all three rhythms, motor, auditory, and visual must be consistent with each other. Dalcroze, pioneer music educator, summarized well when he stated that the perfection of physical resources results in clarity of perception (Dalcroze, 1967, p. 39).

\section{$\underline{\text { Summary and Conclusions }}$}

The available research evidence and reports of educational practice which have been reviewed seem to suggest that a positive relation exists between perfection of the auditory sense and reading. Many studies suggest that the component of rhythm, either auditory or kinesthetic, or in combination, can be used to good advantage in the development of language skills, specifically reading, and especially with children who are experiencing learning disabilities. Rhythm and its relation to reading has not been widely researched and seems to merit investigation on the basis of the attention it receives. 
However, there also are controversial statements in the literature regarding auditory training. Rees (1973) and Hammill and Larsen (1974) caution against emphasis on auditory training on the basis that there is "no hard core of evidence that an auditory factor underlies language or learning disorders, notwithstanding clinical and educational procedures" (Rees, 1973, p. 304). Rees suggests the possibility of a cognitive versus a linguistic or modal problem. Hammill and Larsen (1974) urge educators to test the validity of the hypothesis that certain auditory skills such as auditory-visual integration, sound blending, memory and discrimination are prerequisites to reading and that deficiencies may cause failure. The conclusions, state Hammill and Larsen, are based on clinical experience and should be evaluated by carefully designed research. The concensus of their review of 33 studies using correlational statistical procedure was that "the measured auditory skills are not usefully related to reading" (Hammill and Larsen, 1974, p. 429). Evidence from one study tends to indicate that the visual channel produces greater learning than the auditory channel in young children, meaning kindergarten to second grade, and mentally retarded and learning disabled children. The auditory mode was preferred by older children with high IQ, and the second grade seemed to be a point at which findings were contradictory (Estes and Huizinga, 1974).

Some recent evidence has emerged that internalization of the intonation pattern of language may have a positive relationship to development of syntax and to reading comprehension. The results of a study by Vogel and McGrady (1975) to assess the 
relationship among intonation, syntactic abilities and reading comprehension indicate a strong correlation, and further study is recommended in this area. The writer feels that some reports of successful techniques stressing speech rhythms and instruction combining melody patterns with rhythm training in integrated language arts instruction may be related to the above mentioned phenomenon.

Considerable evidence is given in the literature that an adaptation of music instruction to the curriculum is advantageous. Nonetheless, one does well to proceed cautiously and not become so enamoured with a method that extraordinary powers are credited to it. Groff (1976), among others, states that, since music and language are both perceptual acts of the ear and the eye, involving attention to selective details, parallels will exist which are not necessarily applicable to the learning process. He urges that reading teachers not displace regular reading instruction with music activities. Perhaps the most balanced and pertinent statement regarding the position of music in the elementary curriculum comes from the Music Educators National Committee on Instruction. Music should be taught primarily because it represents a cultural heritage, brings joy and solace, and elevates and exalts the human spirit; music and the other arts should be taught primarily for their own sake. The committee acknowledges that music, being a complex and diverse medium, may serve functions outside of its own sphere. Although its influence on human behavior is somewhat substantiated and its use as a methodological tool in teaching academic skills lacks adequate controls and is technically 
inadequate, yet the hypotheses are not without merit and warrant further examination. According to the committee, music is basic in education and deserves a prominent position in the curriculum, and "ancillary contributions might be highly valued in some communities" (Position Paper of the Music Educators Nationa1 Committee on Instruction, 1977). 
CHAPTER III

RESEARCH DESIGN

\section{Introduction}

This is a correlational study, the purpose of which is to discover the extent to which reading proficiency and rhythm ability are related. This chapter describes the population and sample chosen for the study, the data required, and the instruments used for collecting the data. A discussion of the procedures for collecting the data and methods of analysis will conclude the chapter.

\section{The Population and Sample}

Reading difficulties become acute during the middle elementary years when increased emphasis is placed on reading for content rather than primarily on development of basic reading skills. This was a major factor in the choice of the grade level selected for this study. The six fifth-grade classrooms of Sylvester Elementary School, Berrien Springs, Michigan, were chosen as a unit for the population, of which all members also constituted the sample. Arbitrary sampling was preferred to random sampling as random sampling would greatly disrupt the normal routine of the participating classrooms. One hundred and fiftythree subjects, aged ten to thirteen years and in the fifth grade participated in the study. A few slow learning students and two 
hearing impaired students for whom tutoring to meet specific needs was provided were incorporated into the traditional classroom setting. Of the 153 subjects of the sample, 137 remained after subjects for whom certain data were unavailable were eliminated from the study. Of these 74 were female and 63 were male.

\section{Data Required}

In order to test the hypotheses five types of data were required. In order to obtain data for a correlational analysis of reading proficiency and rhythm ability it was necessary to collect a reading achievement score and a measure of rhythm ability from each subject. Age, sex and an indication of each subject's overall mental ability were also required.

Reading achievement scores and composite achievement scores were obtained from the Iowa Tests of Basic Skills, Form Five, which had been administered to all fifth-grade students the previous semester. Reading scores were used as measures of reading ability. The overall achievement score was used to subdivide the sample into high, average, and low ability groups. Rhythm ability scores were obtained by testing the subjects with the rhythm subtest of the Drake Musical Aptitude Tests. Age and sex of each subject were obtained at the time of testing.

\section{Instruments Used for Collecting Data}

This section will describe the lowa Tests of Basic Skills, followed by a description of the Drake Musical Aptitude Tests rhythm subtest. The Iowa Tests of Basic Skills, Form Five, yield a composite achievement score, indicating the functional level of 
mental ability and grade equivalent scores for each subtest area of skills in vocabulary, reading comprehension, language skills, workstudy skills, and arithmetic. The Iowa Tests of Basic Skills is not a generalized achievement battery but is an evaluation of intellectual skills and abilities involved in the above named areas. Writers of the test manual feel that the test is evaluative, testing generalized educational skills over a wide range of ability, versus mastery of facts or topics. Overlapping segments of a continuous, homogenous test for each skill form the appropriate test for each grade level in grades three through nine. Test booklets for each skill tested are used with separate answer sheets that can be machine or hand scored. A brief summary of each subtest follows: 1. Vocabulary. An attempt is made to maintain an equal balance in the vocabulary test between nouns, verbs and adjectives. Test items consist of a stimulus with a choice of four response items.

2. Reading. The reading test is designed to evaluate specific comprehension skills involved in grasping details and purpose, analyzing organization and evaluating a reading selection. The emphasis is on understanding and drawing inferences. The seven to nine reading selections per grade are from a variety of sources: newspapers, magazines, encyclopedias, government publications, textbooks, and literary works. Most of the material is narrative; some poetry selections are included. Forms three, four and five deal largely with comprehension of details and understanding and drawing inferences. Some of the aspects of comprehension aimed at are sense, feeling, tone, 
Intention. Functionally the test measures vocabulary and verbal inference. The score for the reading subtest probably represents a level of comprehension with an element of speed (Iowa Tests of Basic Ski11s, 1971).

3. Language Skills. Skills in spelling, capitalization, punctuation and usage are evaluated with "find-the-error" type questions.

4. Work-study Skills. Graphic material, reference material, tables and maps are used to assess work and study skills.

5. Arithmetic. The arithmetic test deals primarily with arithmetic concepts and problem solving.

The Iowa Tests of Basic Skills are carefully constructed and claim high reliability. Reliability coefficients for the major tests range from .89 to .96 , and from .76 to .93 for the subtests. Reliability coefficients for the composite tests for the different grades are .97 to .98 .

Intercorrelations among the subtests range from .74 to .93 . Reading, language skills and work-study skills have the highest intercorrelations with other subjects with coefficients between .91 and .92 . The reliability coefficients quoted are split-half estimates; test-retest measures may be somewhat lower (Iowa Tests of Basic Skills, 1971). Grade-equivalent scores for norming are given, as well as individual percentile norms for each grade. Standardization is based on a sample of 120,000 pupils in diverse United States school systems.

To test the perception of rhythm, the rhythm subtest of the Drake Musical Aptitude Tests was used. Factors in the choice of 
this test were suitability of the test as an instrument measuring ability versus achievement, appropriateness to age and experience of the subjects, and conciseness and ease of administration. The Drake Musical Aptitude Tests are provided on a $331 / 3 \mathrm{rpm}$ record. Any person familiar with testing procedure and aided by the explicit instructions of the test manual can administer the tests. Time required for the rhythm test is thirty to forty minutes. The Drake tests are appropriate for persons age eight years to adult, and can be administered to groups of thirty persons at one time. The rhythm test may be administered alone, or in combination with the musical memory test for purposes of determining musical aptitude. For use in this study, only the rhythm test was administered. The rhythm test items consist of a given metronome beat followed by an interval of time in wich the subject is to maintain the beat mentally by continuing to count at the same rate. A feeling for the tempo is established, the beat fades out and the subject maintains the tempo mentally until told to stop. He then records his count on a form response sheet.

Form $A$ and Form $B$ of the rhythm test are not equivalent. Form A measures rhythm in simple form; Form B, considered to be more valid, is also more difficult as it involves a distracting tempo. Authors of the test manual suggest use of both forms for a reliable score.

Percentile norms are provided for both forms of both tests and are based on about 5000 cases from diverse backgrounds. While age is not a factor in determining percentile scores for the rhythm. test, musical training is taken into consideration. 
The authors of the manual claim high validity in terms of measures of aptitude for musical training. The Drake Musical Aptitude Tests are not tests of achievement, specific acquired skills, or interest in music, but of ability. Reliability coefficients based on scores of persons with musical training are in the $.90 \mathrm{~s}$, untrained groups are somewhat lower, in the $.70 \mathrm{~s}$ and $.80 \mathrm{~s}$. Validity coefficients based on norm groups drawn from the United States, England, Belgium and India, range from .31 to .91 , with a majority attaining greater value than .58 (Drake Musical Aptitude Tests, Manual).

The rhythm test is designed as a measure of the psychological characteristic by that name rather than the musical term of the test material, according to writers of the manual (p. 13). It is not merely a test of sameness and difference, but of the ability to maintain a rhythm. The test does not measure perceptual comparison of two beats, but rather a response of maintaining a predetermined beat.

\section{Procedures for Collecting Data}

Because of the proximity to Andrews University and its excellent rapport with the University and its related research projects, the Berrien Springs Public School system was a primary choice as the population for this research study. Initial arrangements to obtain the required data for the study were made with Alfred Berg, principal of Sylvester Elementary School.

The Iowa Tests of Basic Skills had been administered on a school-wide basis the previous semester by school personnel. Since 
the resulting data fit quite precisely the needs of the study, permission was granted by Berg for access to the records of the achievement test results of the participating students. Since the remaining data, the rhythm ability scores, could be obtained only by testing, arrangements were made with Berg and the music teacher, Laura Jean Sil1, to conduct group testing during the students' weekly classroom music lesson on two consecutive mornings of one week. Data on age and sex were obtained from the students at the time of testing.

The rhythm subtest of the Drake Musical Aptitude Tests was administered to each of the six groups of fifth-grade students during their regularly scheduled music class. Each group met at its regularly scheduled music lesson time in a room equipped for music instruction and were introduced as a group by their music instructor to the examiner and another person assisting with the administration of the test. The same two persons conducted each of the testing sessions. The examiner then introduced the rhythm test, distributed mimeographed response forms and pencils and gave instructions preparatory to the testing procedure. The students were asked to record their age and sex on the form. Further instructions for taking the test were given according to the directions given in the manual for the Drake Musical Aptitude Tests by the assisting examiner, who was also a person with musical training.

A monaural phonograph was used to play the rhythm test of the Drake Musical Aptitude Tests. The entire test, including sample items, was given on the record. The number of each test 
Item was announced on the record. Each item consisted of a metronome beat accompanied by a male voice counting along with the beat. A short interval of time followed each item in which the subject was to continue counting at the same rate to maintain the tempo. When the voice said "stop" each subject was to record his count on the numbered answer sheet. Form $B$ was similar, with the exception that the interval of silent time was now occupied by a distracting beat against which the subject was to maintain the original tempo given in the test item. The mimeographed answer sheets had two vertical columns of numbered spaces for both Form $A$ and Form B.

The students were very cooperative, and disturbances were minimal. A few distracting feet-tapping noises were eliminated with quiet cues to the involved persons. At one point, a group of students playing outdoors ran noisily past the window, causing momentary distraction. One student entered the room after testing had begun, but this did not seem to distract many of the students. At the end of each period of testing answer sheets and pencils were collected prompt1y.

The rhythm subtest was administered to all six groups of students on successive days by the same two examiners and in a reasonably consistent manner. Other than the students, the two examiners and the music instructor were the only persons present during testing.

A master 1ist of data was compiled, initially collecting for each student enrolled in the fifth grade, comprehensive achievement scores and reading comprehension scores from the 
Iowa Tests of Basic Skills from a master list on file at the school. After testing was completed, rhythm scores, age and sex of each student were added to the master list of data. After all data were recorded, the data were grouped according to sex. The resulting two groups were further subdivided into high, average and low achievement groups according to composite achievement scores resulting from the Iowa Tests of Basic Skills.

\section{Analysis Methods}

For purpose of the analysis the hypotheses are stated in the null form. Hypothesis one states that there will be no significant positive correlation between reading achievement and auditory rhythm ability.

The Pearson product-moment correlation coefficient was used to test the hypothesis for the complete group of students and also for the eleven subgroups according to sex and ability level as measured by overall achievement by the Iowa Tests of Basic Skills.

Hypothesis two states that there will be no difference between the correlation coefficients for subgroups of students according to sex and ability level. The $Z$ test of comparison of correlation coefficients from two independent samples was used for each comparison. Because of the small number of subjects in the subgroups, the level of probability was set at .10 to achieve reasonable power. 


\section{CHAPTER IV}

\section{PRESENTATION AND ANALYSIS OF DATA}

Initially the data were recorded as they were obtained from classroom units. When all the data had been recorded, they were grouped by sex and further subdivided into high, average and low overall ability groups, using the grade equivalence scores of achievement from the Iowa Tests of Basic Skills. For both reading and achievement scores, values greater than 5.7 were designated as high achievement. Grade equivalence scores between 5.7 and 4.7 inclusive were designated as average achievement. Scores below 4.7 were designated as low achievement. The boys' group had 18, 24, and 21 entries respectively, totaling 63. The girls' group had 22, 34, and 19 entries respectively, totaling 75 . Of the 138 subjects participating in the study, 58, or 42 percent were in the average range. The high and low categories each had 40 entries, or 29 percent each of the 138 subjects who participated in the study. After grouping the data, but before analysis, the data for one subject in the high ability girls' group was accidentally omitted. Consequently, the entries for the girls' group totaled 74, and the data of 137 subjects was used in the actual analysis. 


\section{Basic Data}

\section{Conversion of Scores}

The rhythm ability score from the Drake Musical Aptitude

Tests is obtained by figuring how far the student's count on an auditory rhythm is removed from the actual count of a beat. Thus, low numerical scores indicate high ability and high numerical scores indicate low ability. In order to avoid a seemingly negative correlation because of the structure of the test scores, these were converted by substracting each rhythm score from 400 . Thus a high score indicates high ability, and a low score indicates low ability. The raw scores of all 137 subjects on the three variables are given in tables 4 to 9 . The rhythm score in the appendix is the unadjusted score.

\section{Mean Scores}

Table 1 gives the mean score of each group and subgroup, by sex and ability level, on the three variables. The rhythm score in the table is the adjusted score.

On comparing the group means for the three ability levels, whether for male or female or combined, there is a clear decrease in rhythm mean scores from high to low ability, and from high to low reading achievement. It would therefore be expected that a significant positive correlation would be found between reading achievement and rhythm ability. 
TABLE 1

(CAN

MEANS ON THE THREE VARIABLES

\begin{tabular}{|c|c|c|c|c|}
\hline & $N$ & Achievement & Reading & $\begin{array}{c}\text { Adjusted } \\
\text { Rhythm }\end{array}$ \\
\hline \multicolumn{5}{|c|}{ High Ability } \\
\hline $\begin{array}{l}\text { Male } \\
\text { Female } \\
\text { Combined }\end{array}$ & $\begin{array}{l}18 \\
21 \\
39\end{array}$ & $\begin{array}{l}65.72 \\
65.29 \\
65.49\end{array}$ & $\begin{array}{l}62.94 \\
68.19 \\
65.77\end{array}$ & $\begin{array}{l}331.17 \\
333.19 \\
332.25\end{array}$ \\
\hline \multicolumn{5}{|c|}{ Average Ability } \\
\hline $\begin{array}{l}\text { Male } \\
\text { Female } \\
\text { Combined }\end{array}$ & $\begin{array}{l}24 \\
34 \\
58\end{array}$ & $\begin{array}{l}51.46 \\
52.21 \\
51.90\end{array}$ & $\begin{array}{l}53.00 \\
54.26 \\
53.74\end{array}$ & $\begin{array}{l}313.50 \\
308.67 \\
310.67\end{array}$ \\
\hline \multicolumn{5}{|c|}{ Low Ability } \\
\hline $\begin{array}{l}\text { Male } \\
\text { Female } \\
\text { Combined }\end{array}$ & $\begin{array}{l}21 \\
19 \\
40\end{array}$ & $\begin{array}{l}38.86 \\
41.05 \\
39.45\end{array}$ & $\begin{array}{l}34.90 \\
37.26 \\
36.02\end{array}$ & $\begin{array}{l}288.71 \\
284.47 \\
286.70\end{array}$ \\
\hline \multicolumn{5}{|c|}{ Total } \\
\hline $\begin{array}{l}\text { Male } \\
\text { Female } \\
\text { Combined }\end{array}$ & $\begin{array}{r}63 \\
74 \\
137\end{array}$ & $\begin{array}{l}51.33 \\
53.05 \\
52.26\end{array}$ & $\begin{array}{l}49.81 \\
53.85 \\
51.99\end{array}$ & $\begin{array}{l}310.28 \\
309.41 \\
309.81\end{array}$ \\
\hline
\end{tabular}

\section{Test of Hypotheses}

Hypothesis One

Hypothesis 1, given in null form, stated that there will be no significant positive correlation between reading achievement and auditory rhythm ability. Product-moment correlation coefficients between reading achievement and rhythm ability were found by 
computer for the boys grouped by high, average, and low achievement, and for the girls grouped by high, average, and low achievement. Table 2 shows the correlation coefficients found for the overall group and each of the subgroups.

TABLE 2

CORRELATION COEFFICIENTS BETWEEN READING ACHIEVEMENT

AND RHYTHM ABILITY FOR ALL GROUPS

\begin{tabular}{lccc}
\hline & Males & Females & Combined \\
\hline High Achievement & $.46 *$ & $.33 *$ & $.39 *$ \\
Average Achievement & -.06 & .12 & .04 \\
Low Achievement & -.08 & .07 & -.01 \\
Total Group & $.35 *$ & $.33 *$ & $.33 *$ \\
\hline
\end{tabular}

*Significant at the .10 level

Overall, the correlation coefficient of .33 is significant, as it is also for the separate boys' group (.35) and girls' group (.33). This agrees with our subjective interpretation of table 1 . There is a positive correlation between reading achievement and rhythm ability. Inspection of the table, however, indicates that, in the achievement subgroups, the correlation is significant for only the high achievers. It would appear that there is a significant relationship between reading achievement and rhythm ability for boys and girls of high achievement level. That is, only among the higher ability students is the relationship strong enough to be predictive for individuals. 


\section{Hypothes is Two}

Hypothesis 2, given in null form, stated that there will be no difference between the correlation coefficients for subgroups of students according to sex and ability level. As the coefficients for average and low achievers were not significantly different from zero, the only meaningful comparisons with respect to this hypothesis are between boys and girls, at the high achievement level and overall. The results are shown in table 3.

TABLE 3

COMPARISONS OF CORRELATION COEFFICIENTS

\begin{tabular}{lcccr}
\hline & Boys & Girls & $\mathrm{Z}$ & $\mathrm{p}$ \\
\hline High Achievement & .46 & .33 & 0.45 & .65 \\
Total Group & .35 & .33 & 0.13 & .90 \\
\hline
\end{tabular}

In neither case does the $\mathrm{Z}$ approach significance, hence, for the two comparisons presented, the null hypothesis is upheld. The relationship is the same for boys and girls. 
CHAPTER V

\section{SUMMARY AND CONCLUSIONS}

The available research evidence and reports of educational practice seem to indicate a trend toward exploration of the role of the auditory modality in development of language skills (Johnson and Myklebust, 1967; Richie and Aten, 1976). Music, and particularly the component of rhythm, are thought to have a beneficial effect on gaining reading skills (Block and Lieberman, 1968; Hurwitz, Wolff, Bortnick and Kokas, 1975). Very limited research is available on this specific relationship. This study was designed to discover, by means of a correlation analysis, the extent to which a relationship exists between rhythm ability and reading achievement in a sample of fifth-grade children. It was hypothesized that a significant positive correlation would exist between rhythm ability and reading achievement, and that there would be no difference in the magnitude of the correlation for children of différent sexes.

Prerequisite to a discussion of rhythm is an overview of audition in relation to learning. Thus, selected literature was reviewed relating factors of audition to acquisition of language skills. Numerous scholarly reports discuss perception, discrimination, memory, and auditory processing. Most researchers agree that these factors are positively related to reading ability 
(McGinitie, 1967; Myklebust, 1954; Richie and Aten, 1976; Wepman, 1960). While many researchers agree that judgments of auditoryvisual equivalence are positively related to reading proficiency (Birch and Belmont, 1964; Kahn and Birch, 1968; Robinson, 1973; Ward, 1977), others believe that auditory-visual integration is not a critical skill in reading, and that undefined factors are responsible for the positive results of sensory integration studies (Bryden, 1972; Vande Voort and Senf, 1973; Vande Voort, Senf and Benton, 1972).

A discussion of rhythm and its relation to language skills, as reported in popular education journals, as well as some wellresearched findings on rhythm and language, conclude the review of selected literature. It appears that rhythm and music, the larger medium to which rhythm is related, are being much experimented with in educational practice, especially as methodological tools in the elementary curriculum and as remedial techniques with children who are experiencing learning difficulties (Block and Lieberman, 1968; Cohen, 1974; Kalishi, 1977; Lehman, 1969; Rejto, 1973; Robison, 1971). Beneficial effects on academic skills through the use of specially designed music education programs have been observed by some educators (Harper et al., 1973; Hurwitz et al., 1975). On a functional level, it is claimed that rhythm aids organization and classification of information received through the senses, and that this function is basic to later learning activities (DeHirsch, Janskey and Langford, 1966; Kephart, 1960). Caution is urged by some researchers against emphasis on auditory training in teaching reading skills (Rees, 1973; Hammill and Larsen, 1974; 
Estes and Huizinga, 1974), since many of the conclusions of the benefits of auditory training are based on clinical experience rather than carefully designed research. However, the enriching effects of music education and rhythm training in the curriculum must not be overlooked.

Six fifth-grade classrooms of Sylvester Elementary School, Berrien Springs, Michigan, participated in the study. Of the 137 subjects participating in the sample, 74 were female and 63 were male. In order to test the hypotheses five types of data were required of each subject: a rhythm ability score, a reading achievement score, sex, age, and an indication of overall ability. The reading achievement score and an overall achievement score were obtained from results of the Iowa Tests of Basic Skills, Form Five, which had been administered the previous semester. The rhythm ability score was obtained by testing the subjects with the rhythm test of the Drake Musical Aptitude Tests. Age and sex of each subject were obtained at the time of testing. All data were recorded on a master chart, and then grouped according to sex. The resulting two groups and the complete group were then further subdivided according to high, average and low overall ability. The Pearson product-moment correlation coefficient was used to test the hypotheses for the entire sample, as well as for the subgroups divided by sex and ability level. Fisher's $z_{r}$ was used for each comparison of correlation coefficients for subgroups of students. Because of the small number of subjects in the subgroups, the level of probability was set at .10 to achieve reasonable power. 


\section{Findings}

It was hypothesized that children who perform well on a reading test would also perform well on a rhythm test, and that there would be no difference in the magnitude of the relationship for either sex. The results of the correlation of scores indicated that a positive relation exists between rhythm ability and reading ability for the sample as a unit. However, in the subgroups, only the high overall achievement groups yielded a significant positive correlation. The significant positive correlation for the composite sample occurs because the higher achievers do score better on the rhythm test than the average and low achievers, as a comparison of their mean scores indicates. It is surprising that, while the rhythm score means for the three ability groups do decrease as ability decreases, it is only for the high ability group that a correlation is seen within the group.

\section{Discussion}

The fact that a significant correlation between rhythm ability and reading achievement exists for the sample as a whole seems to indicate the presence of a relationship other than overall ability. For children of this sample, a relationship between rhythm ability and reading achievement does exist, as indicated by the significant positive correlation for the total group. Children who read well also perform well on a rhythm test. As indicated by the decreasing mean scores for rhythm and reading, children of this sample who did not read well also did not perform well on the rhythm test. However, the predictive value of rhythm ability is 
limited to the high overall achievement level where a significant positive correlation occurred.

It is somewhat surprising that no correlation occurs on the average achievement level, and that the difference in the size of the correlation coefficients of the high achievement groups (.39) and the average achievement groups (.04) is so great. Perhaps a larger sample would have yielded a better distribution of scores and thus show correlations approaching a level of significance in the average achievement groups.

A further limitation of the study which may have affected the correlation of scores is the lag between administration of the rhythm test, which was administered during the second semester of the school year, and the achievement tests which were administered the previous semester. Development is never stationary, and the relation between any two factors can change over a period of time as one or both areas attain a more complex level of development.

\section{Recommendations}

The results of the study have demonstrated that a relationship exists between reading achievement and rhythm ability, but that rhythm ability has predictive value only on levels of high overall ability. Since it is a study of very limited scope and size, a similar study of greater magnitude might result in a more adequate assessment of the relationship. Other variables which would provide interesting insights into the nature of the relationship are the effects of intelligence, musical training, age versus grade placement, and race. A study exploring the relationship on 
other levels of development, such as the primary grades, high school, and adult would also be useful. A study of the rhythm ability of children experiencing reading difficulties, and who are at least one grade below their reading level, might be profitable. It remains an unanswered question if improvement of rhythm ability has beneficial effects on other areas such as reading skills. Perhaps the most effective and meaningful investigation of this topic would be a longitudinal study of the effects of rhythm training on language skills. The effects of certain types of music training on other academic skills have been referred to in the 1iterature (Hurwitz et at., 1975; Herbert, 1974). It would be beneficial to capitalize on the findings and determine just which elements or factors are responsible for the seemingly good effects. Perhaps rhythm is among them.

Similar investigations should be made with children evidencing learning disabilities. The literature of ten refers to the apparent lack of rhythm ability in such children (Drake, 1964; Johnson and Myklebust, 1967). A longitudinal study of the effects of rhythm training or an investigation into the nature of the relation of rhythm ability to reading skills in learning disabled children would be helpful. Children with learning disabilities need much insight and understanding of their peculiar difficulties. If a vital factor can be defined and exploited, it should be done with expedience.

Rhythm ability, coupled with high overall ability, may have merit as a predictive tool in indicating children who are likely to perform well on reading tasks. However, regarded as a diagnostic 
tool, rhythm ability is only one of many interrelated factors accompanying learning difficulties. For individual children, the predictive value of rhythm ability is questionable and should be used with caution.

The relationship of rhythm ability to other skills is poorly understood, yet its inclusion in the curriculum is not without merit. Rhythm is a fundamental element. The wholistic development of persons demands skills in many areas and implies interrelation of parts. Any feasible means to encourage, stimulate, and promote the development of mental powers and various useful skills should be employed. As skills are developed, confidence and the motivation to succeed in other areas are encouraged. Furthernore, an understanding of rhythm and its effects adds a great deal of pleasure to life. Rhythm training might be most beneficial when it is a part of an educational program encouraging balanced development of physical and mental faculties. Although this study has shown a correlation between rhythm perception and reading ability, it is not necessarily a cause-effect relationship. The concept that rhythm training promotes development of language skills is inadequately defined and not well supported, and should be further studied. 

TABLE 4

RAW DATA FOR HIGH ACHIEVING GIRLS $\mathrm{N}=21$

\begin{tabular}{llll}
\hline $\begin{array}{l}\text { Achievement } \\
\text { Score }\end{array}$ & Reading Score & Rhythm Score \\
\hline 75 & 78 & 30 & $(370)$ \\
72 & 78 & 79 & $(321)$ \\
71 & 75 & 37 & $(363)$ \\
70 & 78 & 60 & $(340)$ \\
69 & 75 & 61 & $(339)$ \\
69 & 73 & 47 & $(353)$ \\
68 & 79 & 79 & $(321)$ \\
68 & 67 & 67 & $(333)$ \\
67 & 64 & 62 & $(338)$ \\
65 & 72 & 90 & $(310)$ \\
64 & 74 & 50 & $(350)$ \\
63 & 72 & 92 & $(308)$ \\
63 & 62 & 63 & $(337)$ \\
63 & 67 & 88 & $(312)$ \\
62 & 61 & 83 & $(317)$ \\
62 & 65 & 51 & $(349)$ \\
62 & 62 & 56 & $(344)$ \\
62 & 58 & 70 & $(330)$ \\
59 & 54 & 89 & $(311)$ \\
59 & 59 & 78 & $(322)$ \\
58 & 59 & 71 & $(329)$ \\
& & & \\
\hline
\end{tabular}

() Adjusted rhythm score 
TABLE 5

RAW DATA FOR AVERAGE ACHIEVING GIRLS

$$
\mathrm{N}=34
$$

\begin{tabular}{|c|c|c|c|}
\hline $\begin{array}{c}\text { Achievement } \\
\text { Score }\end{array}$ & Reading Score & Rhythm & Score \\
\hline 57 & 59 & 57 & $(343)$ \\
\hline 57 & 68 & 83 & $(317)$ \\
\hline 57 & 51 & 31 & $(369)$ \\
\hline 57 & 56 & 72 & $(328)$ \\
\hline 56 & 58 & 62 & (338) \\
\hline 56 & 57 & 75 & (325) \\
\hline 56 & 56 & 59 & $(341)$ \\
\hline 56 & 58 & 159 & (241) \\
\hline 56 & 61 & 82 & $(318)$ \\
\hline 55 & 48 & 77 & (323) \\
\hline 55 & 57 & 82 & $(318)$ \\
\hline 54 & 51 & 145 & (255) \\
\hline 54 & 63 & 38 & $(362)$ \\
\hline 53 & 48 & 72 & $(328)$ \\
\hline 53 & 52 & 93 & $(307)$ \\
\hline 53 & 55 & 226 & (174) \\
\hline 53 & 52 & 85 & (315) \\
\hline 52 & 59 & 73 & $(327)$ \\
\hline 52 & 53 & 103 & $(297)$ \\
\hline 51 & 58 & 60 & $(340)$ \\
\hline 50 & 52 & 100 & $(300)$ \\
\hline 50 & 59 & 135 & $(265)$ \\
\hline 50 & 52 & 49 & (351) \\
\hline 49 & 50 & 68 & (332) \\
\hline 49 & 55 & 51 & (349) \\
\hline 49 & 54 & 285 & (115) \\
\hline 49 & 46 & 77 & (323) \\
\hline 49 & 48 & 166 & (234) \\
\hline 48 & 42 & 124 & $(276)$ \\
\hline 48 & 51 & 45 & (355) \\
\hline 48 & 51 & 62 & (318) \\
\hline 48 & 53 & 103 & (297) \\
\hline 48 & 53 & 55 & (345) \\
\hline 47 & 59 & 51 & (349) \\
\hline
\end{tabular}

() Adjusted rhythm score 
TABLE 6

RAW DATA FOR LOW ACHIEVING GIRLS $\mathrm{N}=19$

\begin{tabular}{llrl}
\hline $\begin{array}{c}\text { Achievement } \\
\text { Score }\end{array}$ & Reading Score & Rhythm Score \\
\hline 46 & 43 & 75 & $(325)$ \\
46 & 39 & 52 & $(348)$ \\
45 & 44 & 108 & $(292)$ \\
43 & 32 & 62 & $(338)$ \\
43 & 35 & 62 & $(338)$ \\
43 & 42 & 93 & $(307)$ \\
43 & 39 & 92 & $(308)$ \\
43 & 35 & 75 & $(325)$ \\
43 & 41 & 188 & $(212)$ \\
42 & 51 & 150 & $(250)$ \\
42 & 41 & 297 & $(103)$ \\
42 & 39 & 244 & $(156)$ \\
41 & 34 & 87 & $(313)$ \\
40 & 42 & 44 & $(356)$ \\
39 & 43 & 38 & $(362)$ \\
37 & 35 & 114 & $(286)$ \\
37 & 34 & 92 & $(308)$ \\
35 & 20 & 86 & $(314)$ \\
30 & 19 & 236 & $(164)$ \\
& & & \\
\hline
\end{tabular}

() Adjusted rhythm score 
TABLE 7

RAW DATA FOR HIGH ACHIEVING BOYS

$\mathrm{N}=18$

\begin{tabular}{llrl}
\hline $\begin{array}{c}\text { Achievement } \\
\text { Score }\end{array}$ & Reading Score & Rhythm Score \\
\hline 78 & 74 & 74 & $(326)$ \\
78 & 84 & 66 & $(334)$ \\
77 & 67 & 68 & $(332)$ \\
71 & 62 & 70 & $(330)$ \\
68 & 62 & 75 & $(325)$ \\
67 & 65 & 79 & $(321)$ \\
66 & 64 & 47 & $(353)$ \\
65 & 66 & 49 & $(351)$ \\
64 & 66 & 67 & $(333)$ \\
64 & 64 & 51 & $(349)$ \\
63 & 63 & 52 & $(348)$ \\
62 & 61 & 80 & $(320)$ \\
62 & 52 & 76 & $(324)$ \\
61 & 66 & 83 & $(317)$ \\
60 & 58 & 42 & $(358)$ \\
60 & 42 & 183 & $(217)$ \\
59 & 58 & 44 & $(356)$ \\
58 & 59 & 33 & $(367)$ \\
& & & \\
\hline
\end{tabular}

() Adjusted rhythm score 
TABLE 8

RAW DATA FOR AVERAGE ACHIEVING BOYS

$$
\mathrm{N}=24
$$

\begin{tabular}{llrl}
\hline $\begin{array}{c}\text { Achievement } \\
\text { Score }\end{array}$ & Reading Score & Rhythm Score \\
\hline 57 & 60 & 67 & $(333)$ \\
57 & 55 & 57 & $(343)$ \\
56 & 63 & 75 & $(325)$ \\
55 & 62 & 95 & $(305)$ \\
55 & 56 & 122 & $(278)$ \\
55 & 47 & 77 & $(323)$ \\
54 & 65 & 54 & $(346)$ \\
54 & 53 & 109 & $(291)$ \\
54 & 58 & 194 & $(206)$ \\
54 & 58 & 76 & $(324)$ \\
53 & 56 & 120 & $(280)$ \\
51 & 55 & 80 & $(320)$ \\
51 & 58 & 33 & $(367)$ \\
49 & 43 & 80 & $(320)$ \\
49 & 47 & 66 & $(334)$ \\
49 & 47 & 68 & $(332)$ \\
49 & 47 & 93 & $(307)$ \\
48 & 53 & 53 & $(347)$ \\
48 & 47 & 72 & $(328)$ \\
48 & 51 & 182 & $(218)$ \\
48 & 50 & 95 & $(305)$ \\
47 & 46 & 74 & $(326)$ \\
47 & 48 & 81 & $(319)$ \\
47 & 46 & 53 & $(347)$ \\
& & & \\
\hline
\end{tabular}

() Adjusted rhythm score 
TABLE 9

RAW DATA FOR LOW ACHIEVING BOYS $\mathrm{N}=21$

\begin{tabular}{llrl}
\hline $\begin{array}{c}\text { Achievement } \\
\text { Score }\end{array}$ & Reading Score & Rhythm Score \\
\hline 46 & 37 & 96 & $(304)$ \\
45 & 41 & 82 & $(318)$ \\
45 & 49 & 77 & $(323)$ \\
44 & 35 & 61 & $(339)$ \\
43 & 31 & 94 & $(306)$ \\
42 & 49 & 145 & $(255)$ \\
42 & 46 & 79 & $(321)$ \\
42 & 29 & 56 & $(344)$ \\
42 & 41 & 141 & $(259)$ \\
38 & 41 & 90 & $(310)$ \\
38 & 21 & 117 & $(283)$ \\
38 & 34 & 115 & $(285)$ \\
37 & 34 & 137 & $(263)$ \\
36 & 19 & 51 & $(349)$ \\
36 & 39 & 208 & $(192)$ \\
35 & 37 & 126 & $(274)$ \\
35 & 39 & 189 & $(211)$ \\
35 & 29 & 58 & $(342)$ \\
34 & 37 & 176 & $(224)$ \\
33 & 16 & 196 & $(204)$ \\
30 & 29 & 43 & $(357)$ \\
& & & \\
\hline
\end{tabular}

() Adjusted rhythm score 


\section{SELECTED BIBLIOGRAPHY}

Alexander, Richard. "Pattern Rate and Interpattern Interval in Development of Matching Simple Auditory-Visual Patterns." Developmental Psychology 13 (July 1977): 332-336.

Allen, Terry; Walker, Karen; Symonds, Laura; and Marcell, Michael. "Intrasensory and Intersensory Perception of Temporal

Sequences During Infancy." Developmental Psychology 13 (May 1977): 225-229.

Anderson, David 0. "Pruning the Fuzziness and Flab from Learning Disabilities Research." Journal of Special Education 10

(Summer 1976): 157-161.

Ashlock, Patrick. Teaching Reading to Individuals with Learning Difficulties: Springfield, Illinois: Charles C. Thomas, 1969.

Badian, Nathlie A. "Auditory-Visual Integration, Auditory Memory, and Reading in Retarded and Adequate Readers." Journal of Learning Disabilities 10 (February 1977): 108-14.

Baker, Georgia Ann P. "Behavior Problem or Auditory Interferences?" Academic Therapy 6 (Summer 1971): 385-89.

Beery, Judith W. "Matching of Auditory and Visual Stimuli in Average and Retarded Readers." Child Development 38 (September 1967): 827-31.

Berry, M. F. Language Disorders of Children: The Basis and Diagnosis. New York: Appleton-Crofts, 1969.

Birch, H.; and Belmont, L. "Auditory-visual Integration in Normal and Retarded Readers." American Journal of Orthopsychiatry 34 (October 1964): 852-861.

Block, Elaine C.; and Lieberman, Janet. "Art and Music: Pathways to Reading." Elementary School Journal 68 (January 1968): 180-87.

Bradley, R. C. "Do Current Reading Practices Stifle Curiosity?" Reading Teacher 22 (February 1969): 448-52. 
Bryden, M. P. "Auditory-visual and Sequential-spatial Matching in Relation to Reading Ability." Child Development 43

(September 1972): 824-32.

Cameron, Rosaline B. "Music as a Means to Learning." Music Journal 28. (March 1970): 59.

- "Piano Music is a Means." Music Journa1 30 (March 1972): 37.

Cohen, Mel. "Move Him into Reading with Music." Instructor 83 (February 1974): 60-62.

Corkin, Suzanne. Abstract of "Serial Ordering Deficits in Inferior Readers." Journal of Learning Disabilities 8 (February 1975): $87-88$.

Critchley, MacDonald. "Developmental Dyslexia: A Constitutional Dyssymbolia." In Word Blindness or Specific Developmental Dyslexia, p. 46. Edited by Alfred Franklin. London: Pitman Medical Publishing Co., 1962.

Dalcroze, Emile-Jaques. Rhythm, Music, and Education. Translated by Harold F. Rubenstein. London: Riverside Press, 1967.

DeHirsch, Katrina; Jansky, Jeannette; and Langford, William S. Predicting Reading Failure. New York: Harper and Row, 1966.

Delacato, Carl H. Neurological Organization and Reading. Springfield, Illinois: Charles C. Thomas, 1966.

Devens, John S. Noise as it Affects the Learning Disabled Child. Houston: Paper Presented at the Twelfth Annual Conference of the Texas Association for Children with Learning Disabilities, 1976.

Drake, Charles. "Reading, Riting, and Rhythm." Reading Teacher 18 (December 1964): 202-05.

Drake Tests of Musical Aptitude, Manual, 2d ed. Chicago: Science Research Associates, 1957.

Dunn, Rita; and Dunn, Kenneth. "Seeing, Hearing, Moving, Touching Learning Packages." Teacher 94 (May-June 1977): 48-51.

Durre11, D.; and Murphey, H. "The Auditory Discrimination Factor in Reading Readiness and Reading Disability." Education 73 (May 1953): 556-60. 
Dykstra, Robert. "Auditory Discrimination Abilities and Beginning Reading Achievement." Reading Research Quarterly 1 (Spring 1966): 5-34.

E1lehamer, Mogens F. "Assessing Progress in Reading in Denmark." In Reading Instruction: An International Forum. Edited by Marion D. Jenkinson. Newark: International Reading Association, 1966.

Encyclopedia of Educational Research, 4th ed. S.v. "Music Education," by E. H. Schneider.

Estes, Robert E.; and Huizinga, Raleigh J. "A Comparison of Visual and Auditory Presentation of a Paired Associate Learning Task with Learning Disabled Children." Journal of Learning Disabilities 7 (January 1974): 35-42.

Falck, Vilma T. "Auditory Processing for the Child with Language Disorders." Exceptional Children 39 (February 1973): 413-16.

Finkenbinder, Ronald L. "A Descriptive Study of the Goldman-Fristoe Woodcock Test of Auditory Discrimination and Selected Reading Variables with Primary School Children." Journal of Special Education 7 (Summer 1973) : 125-131.

Fitouri, Chadly. "New Ways to Promote Reading." Unesco Courier (July 1972): 16-21.

Flynn, Pauline T.; and Byrne, Margaret C. "Relationship between Reading and Selected Auditory Abilities of Third-grade Children." Journal of Speech and Hearing Research 13 (December 1970): 731-40.

Ford, M. P. "Auditory-visual and Tactile-visual Integration in Relation to Reading Ability." Perceptual and Motor Skills 24 (June 1967): 831-41.

Friedman, Judith B.; and Gillooley, William B. "Perceptual Development in the Deaf and Reading." Journal of Special Education 11 (February 1977): 347-354.

Gallagher, J. J. The Tutoring of Brain Injured Mentally Retarded Children. Springfield, Illinois: Charles C. Thomas, 1960.

Gibbs, Mary E1len. "The Coach Teaches Reading Through Music." Journal of Reading 14 (October 1970): 23-25.

Gray, William Scott. Summary of Investigations Relating to Reading. Chicago: University of Chicago, 1925.

Groff, Patrick. "The Effect of Music on Reading." Reading Horizons 17 (February 1976): 20-24. 
Hamm, Ruth Pollock. "Reading in Rhythm." Instructor 80 (March 1971): 48 .

Hammi11, Donald D.; and Larsen, Stephen C. "The Relationship of Selected Auditory Perceptual Skills and Reading Ability." Journal of Learning Disabilities 74 (August-September 1974): 429-434.

Hande1, S.; and Yoder, D. "The Effects of Intensity and Interval Rhythms on the Perception of Auditory and Visual Temporal Patterns. Quarterly Journal of Experimental Psychology 27 (February 1975): 111-22.

Harper, Andrew; Flick, Mary; Taylor, Karen; and Waldo, Renee. "Education Through Music." Phi Delta Kappan 54 (May 1973): 628-29.

Harris, Albert J. How to Increase Reading Ability, 4th ed. New York: David McKay Co., 1962.

Herbert, Gwynneth F. "Education Through Music." Slow Learning Child: The Australian Journal on the Education of Backward Children 21 (March 1974): 15-23.

Hurwitz, Irving; Wolff, Peter; Bortnick, Barrie; Kokas, Klara. "Non-musical Effects of the Kodaly Music Curriculum in Primary Grade Children." Journal of Learning Disabilities 8 (March 1965): 167-74.

Iowa Tests and Basic Skills: Manual for Administrators, Supervisors, and Counselors. Boston: Houghton-Mifflin Co., 1964 .

Iowa Tests of Basic Skills: Teachers' Guide for Administration, Interpretation, and Use. Boston: Houghton-Mifflin Co., 1971.

Johnson, Betty L. "Make Time for Music." Teacher 93 (January 1976): 86-87.

Johnson, Doris J.; and Myklebust, Helmer R. Learning Disabilities: Educational Principles and Practices. New York: Grune and Stratton, 1967.

Jorgensen, Gera1d W.; and Hyde, E1izabeth M. "Auditory-visual Integration and Reading Performance in Lower Social. Class Children." Journal of Educational Psychology 66 (October 1974): 718-25.

Jusczyk, Peter W. "Rhymes and Reasons: Some Aspects of the Child's Appreciation of Poetic Form." Developmental. Psychology 13

(November 1977): 599-607. 
Kahn, Dale; and Birch, Herbert. "Development of Auditory-visual Integration and Reading Achievement." Perceptual and Motor Skills 27 (October 1968): 459-468.

Kaliski, Lotte. "Auditory-vocal Activation: A Tool for Teaching Children with a Specific Learning Disability." Journal of Learning Disabilities 10 (April 1977): 210-18.

Ka1lan, Cynthia. "Rhythm and Sequencing in an Intersensory Approach to Learning Disability." Journal of Learning Disabilities 5 (January 1972): 286-295.

Karlin, Robert. Teaching Elementary Reading: Principles and Strategies. New York: Harcourt Brace Jovanovich, 1971.

Kephart, Newe11, C. The Slow Learner in the Classroom. Columbus, Ohio: Charles E. Merrill Books, 1960.

Lee, Gerry; and Young, Virginia. "Auditory Versus Visual: A Dual Modality Theory." Kappa Delta Pi Record 11 (October 1974): 28-30.

Lehman, Joan. "Motivate with Music." Grade Teacher 86 (May 1969): 78-82.

Lundin, Robert W. An Objective Psychology of Music, 2d ed. New York: The Ronald Press Co., 1967.

MacGinitie, Walter H. "Auditory Perception in Reading." Education 87 (May 1967): 532-38.

McDonald, Dorothy. "Music and Reading Readiness." Language Arts 52 (September 1975) : 872-76.

Moore, Nancy. "Diagnosis? Hyperkinesis. Prescription? Music!" Music Journa1 27 (November 1969): 29.

Mueh1, Siegmar; and Kremenak, Shirley. "Ability to Match Information within and between Auditory and Visual Sense Modalities and Subsequent Reading Achievement." Journal of Educational Psychology 57 (1966): 230-238.

Myklebust, Helmer. Auditory Disorders in Children. New York: Grune and Stratton, 1954.

Nober, Linda. "Auditory Discrimination and Classroom Noise." Reading Teacher 27 (December 1973): 288-91.

Oakland, Thomas; Williams, Fern; and Harmer, William. "A Longitudinal Study of Auditory Perception and Reading Instruction with First-grade Negro Children." Journal of Special Education 7 (Summer 1973): 141-54. 
Position Paper of the Music Educators National Committee on Instruction." Music Educators' Journal 63 (May-April 1977): 59.

Price, Landon D. "The Trouble with 'Poor Auditory Discrimination."' Academic Therapy 8 (Spring 1973): 331-37.

Rampp, Donald I. "Auditory Perceptual Disturbances." In Communicative Disorders, pp. 297-329. Edited by Alan Weston. Springfield, Illinois: Thomas Publishers, 1971.

Rampp, Donald L.; and Covington, Jan R. "Auditory Perception, Reading, and the Initial Teaching Alphabet." Journal of Learning Disabilities 5 (October 1972): 497-500.

Rees, Norma. "Auditory Processing Factors in Language Disorders" The View from Procrustes' Bed." Journal of Speech and Hearing Disorders 38 (August 1973): 304-15.

Reilly, D. H. "Auditory-visual Integration, Sex and Reading Achievement." Journal of Educational Psychology 62 (December 1971): 482-486.

Rejto, Alice. "Music as an Aid in Remediation of Learning Disabilities." Journal of Learning Disabilities 6 (May 1973): 15-24.

Richie, Dolores J.; and Aten, James L. "Auditory Retention of Non-verbal Sequential Stimuli in Children with Reading Disabilities." Journal of Learning Disabilities 9 (May 1976) : 312-18.

Robinson, Helen M. "Visual and Auditory Modalities Related to Methods for Beginning Reading." Reading Research Quarterly 8 (Spring 1973): 7-39.

Robison, Doris E. "There's Therapy in Rhythm." Music Educators' Journa1 57 (March 1971): 42.

"Role of Music in the Total Development of the Child." Music Educators' Journal 63 (Apri1 1977): 59.

Rosenkrantz, Peggy. "Perceptual-Motor Development: Are You Doing Your Part?" Music Educators' Journal 61 (December 1974): 57-59.

Rosner, Jerome. "Language Arts and Arithmetic Achievement and Specifically Related Perceptual Skills." American Educational Research Journal 10 (Winter 1973): 59-67.

Rudnick, M.; Sterrit, G. M.; and Flax, M. "Auditory and Visual Rhythm Perception and Reading Ability." Child Development 18 (June 1967): 581-588. 
Schon, E1izabeth; and $0^{\prime B r i e n, ~ E m m a ~ L o u . ~ R h y t h m s ~ i n ~ E l e m e n t a r y ~}$ Education. New York: A. S. Barnes and Co., 1951.

Segel, Ruth. "The Haptic Approach in Practice." Academic Therapy 12 (Winter 1976-77): 219-24.

Senf, Gerald M.; and Freund1, Pamela. "Memory and Attention Factors in Specific Learning Disabilities." Journal of Learning Disabilities 4 (February. 1976): 94-106.

Spache, George D.; and Spache, Evelyn. Reading in the Elementary School, 2d ed. Boston: Allyn and Bacon, 1971.

Spache, George D.; and Spache, Evelyn. Reading in the Elementary School, 4th ed. Boston: Allyn and Bacon, 1977.

Sterritt, G. M.; and Rudnick, M. "Auditory-visual Rhythm Perception in Relation to Reading Ability in Fourth-grade Boys." Perceptual and Motor Skills 22 (1.966): 859-64.

Strag, Gerald A.; and Richmond, Bert 0. "Auditory Discrimination Techniques for Young Children." Elementary School Journal 73 (May 1973): 447-53.

Strang, Ruth. Reading Diagnosis and Remediation. Newark: International Reading Association Research Fund, 1968.

Thompson, Lloyd J. Reading Disability. Springfield, Illinois: Charles C. Thomas, Publisher, 1966.

Uh1, Gladys C. "Sing-ing Helps Chil-dren Learn How to Read." Music Educators' Journal 56 (December 1969): 45-46.

U.S. Department of Health, Education and Welfare. Central Processing Dysfunctions in Children: A Review of Research, by J. C. Chalfant and M. A. Schefflin. Washington, D.C.: Government Printing office, 1969.

Vande Voort, Lewis; and Senf, Gerald M. "Audio-visual Integration in Retarded Readers." Journal of Learning Disabilities 6 (January 1973) : 170-179.

Vande Voort, Lewis; and Senf, Gerald M. "Audio-visual Integration in Retarded Readers." Journal of Learning Disabilities 6 (March 1973): 49-58.

Vande Voort, Lewis; Senf, Gerald; and Benton, Arthur L. "Development of Audio-visual Integration in Normal and Retarded Readers." Child Development 43 (December 1972): 1260-72.

Vernon, Magdalen. Reading and its Difficulties: A Psychological Study. Cambridge: The University Press, 1971. 
65

Voge1, Susan A.; and McGrady, Harold J. "Recognition of Melody Patterns in Good and Poor Readers." Elementary English 52 (March 1975): 414-18.

Wagner, Rudolph F. Dyslexia and Your Child. New York: Harper and Row, 1971.

Ward, L. 0. "Variables Influencing Auditory-visual Integration in Normal and Retarded Readers." Journal of Reading Behavior 9 (Fall 1977): 290-295.

Wepman, Joseph. "Auditory Discrimination, Speech and Reading." Elementary School Journal 60 (March 1960): 325:32.

Yaakob, Parthena M. "Music and Reading." Elementary English 50 (April 1973): 577-78. 